\title{
A study to calculate Prevalence of Adult Attention Deficit Disorder in medical \& para-medical students of Central India and its association with various risk factors
}

\author{
Goutam Pritesh ${ }^{1}$, Kaushal Rituja ${ }^{2}$, Goutam Mahima ${ }^{3}$ \\ ${ }^{1}$ Assistant Professor, Department of Neuro Psychiatry, LNMC \& RC, Bhopal. \\ ${ }^{2}$ Assistant Professor, Department of Community Medicine, LNMC \& RC, Bhopal. \\ ${ }^{3}$ Tutor, Department of Community Medicine, LNMC \& RC, Bhopal. \\ Corresponding author: Rituja Kaushal \\ Email-dr.rituja@gmail.com
}

\begin{abstract}
Background: To resolve the mystery of Attention Deficit Hyperkinetic Disorder (ADHD) in adults and to assess its prevalence $\&$ association with various risk factors.

Methodology: This cross sectional analytical study was carried out with specific inclusion \& exclusion criteria on different selected variables. This study was undertaken in the campus of R D Gardi Medical College, Ujjain over medical \& paramedical students. Chi square qualitative statistical analysis was done to evaluate the association of risk factors with the outcome of disease.

Results: The prevalence of ADHD in the study group was found to be $15.9 \%$ (56 out of 353 patients). The most common type of ADHD found in the study population was - Inattentive type (50\%) - 28 out of 56, followed by Hyperactive type (18\%) - 10 out of 56 , Combined type (32\%) - 18 out of 56 . Among the diagnosed 56 Adult ADHD patients 59\% were males and 41\% were females. Level of education was found to be a statistically significant factor in association with occurrence of ADHD in adulthood. Other factors considered in study like age, gender, presence or absence of other co- morbid psychiatric disorders were not found to be statistically significant in association with ADHD. Also variables of past history like rash driving, road traffic accidents, frequent quarrels, substance abuse or learning difficulties in school were not found to be significantly associated with adult ADHD in our study.

Conclusions: It was concluded that such studies should be undertaken frequently at different locations in different time frames to tackle this devastating problem in early stages.
\end{abstract}

Keywords: Adult ADHD, Prevalence, Risk factors, medical students, paramedical students

(Paper received $-16^{\text {th }}$ January 2018, Peer review completed $-10^{\text {th }}$ February 2018)

(Accepted $-12^{\text {th }}$ February 2018)

\section{INTRODUCTION}

Few researchers still point Attention Deficit Disorder (ADD) as a simple behavior disorder. Increasingly, specialists are recognizing that it is a complex syndrome of impairments in development of the brain's cognitive management system, or executive functions. This disorder affects one's ability to 1) Organize and get started on tasks. 2) Attend to details and avoid excessive distractibility 3) Regulate alertness and processing speed 4) Sustain and, when necessary, shift focus 5) Use short-term working memory and access recall 6) Sustain motivation to work 7) Manage emotions appropriately [1].

In routine life, this cluster of cognitive functions synchronizes, often without our conscious involvement, in integrated and dynamic ways to complete a wide variety of tasks. They don't work continuously at peak for any of us; everyone faces difficulty with any of them at any instance of time. However, those diagnosed 
with ADD are substantially more impaired in their ability to use these executive functions than are most other people of the same age and developmental level [1].

The six executive functions that work together in various combinations are Activation - organizing, prioritizing, and activating for work. Focus: focusing, sustaining and shifting attention to tasks. Efforts: regulating alertness and sustaining effort and processing speed. Emotion: managing frustration and modulating emotions. Memory: using working memory and accessing recall. Action: monitoring and selfregulating action [1].

Because normal development of executive functions is not complete until late adolescence or early adulthood, it is not always possible to identify, during childhood, students with impairments in these functions. Some students do not manifest their ADD impairments in noticeable ways until they encounter the more demanding world of high school, where they may be unable to cope with the ongoing conflicts and demands of study, classroom performance, homework in several subjects, and family and social interactions. Other students with ADD do not have noticeable symptoms until even later. Their parents may have built such successful compensatory safety net around them that their ADD impairments do not become apparent until the support system is suddenly removed-as when the student moves away from home to attend a college or university: medications for ADD may help alleviate symptoms, but only for those hours of the day when the medication is active in the brain. During these times, some students under treatment can perform most self-management tasks quite well. For others, medication alone is not sufficient [1-2].

ADHD starts in early childhood but $\sim 20 \%$ cases are reported to persist in adulthood [2]. Adult ADHD remains under reported/ under diagnosed, for lack of suspicion of its existence in adulthood [2-3]. Research suggests that the symptoms of ADHD can persist into adulthood, having a significant impact on the relationships, careers, and even the personal safety of patients who may suffer from it [4-7]. Because this disorder is often misunderstood, many people who have it do not receive appropriate treatment and, as a result, may never reach their full potential. Part of the problem is that it can be difficult to diagnose, particularly in adults.

To screen this disorder in any population, the Adult ADHD Self-Report Scale (ASRS-v1.1) Symptom Checklist was developed in conjunction with the World Health Organization (WHO), and the Workgroup on Adult ADHD. The Symptom Checklist is an instrument consisting of the eighteen DSM-IV-TR criteria. Six of the eighteen questions were found to be the most predictive of symptoms consistent with ADHD. These six questions are the basis for the ASRS v1. Insights gained through this screening may suggest the need for a more in-depth clinician interview. The checklist takes about 5 minutes to complete and can provide information that is critical to supplement the diagnostic process. In routine various risk factors are assessed to evaluate impulsivity, cognitive impairment, hyperactivity, learning problems, attentional problems and oppositional conduct [8].

This study was undertaken to find out the prevalence of Adult ADHD in medical and paramedical students and to study the association of certain variables with Adult ADHD.

\section{METHODOLOGY}

Design wise it is a cross sectional analytical study. Study was conducted over a period of 2 years (20132014) in the campus of RD Gaardi Medical College, Ujjain which is a part of central India. Based on qualitative research formula for sample size calculation $\left(4 \mathrm{PQ} / \mathrm{L}^{2}\right)$ sample size was estimated at 353 . Inclusion criteria for study population included 353 medical students belonging to MBBS, Physiotherapy and Nursing courses of either gender and $>18$ yrs of age who consented for the study. Patients found to be positive on ASRS scale (as screening tool with sensitivity of $68.7 \%$ and specificity of $99.5 \%)^{8}$ for ADHD were interviewed in detail by neuropsychiatrist and were diagnosed as ADHD according to DSM-IV-TR criteria. Predesigned \& pre tested semi structured questionnaire was used as probe to reveal relevant information regarding variables under study.

Variables under study like socio-demographic data and details of illness were recorded, pooled, tabulated and subjected to statistical analysis. 


\section{STATISTICAL ANALYSIS}

Measures of mean \& standard deviation for continuous data and Chi square test for qualitative variables were used as statistical methods. Study was conducted after taking clearance from institutional ethical committee. Verbal consent was taken from participants and confidentiality of data was maintained.

\section{RESULTS}

\section{Socio demographic details}

Study sample was N=353 belonging to MBBS, Physiotherapy (BPTh) and Nursing courses. Calculated mean age of the patients $=20.05( \pm 2.17)$ years. Course wise distribution of students was MBBS -272 $(77 \%)$, BPTh $-56(16 \%)$ and Nursing $-25(7 \%)$. Total participating males were $-176(49.9 \%)$ and females were 177 (50.1\%). Total participants belonging to rural area were - $91(26 \%) \&$ urban area- $262(74 \%)$. The prevalence of ADHD in the study group was found to be $15.9 \%$ (56 out of 353 patients). The most common type of ADHD found in the study population was - Inattentive type (50\%) - 28 out of 56, followed by Hyperactive type $(18 \%)-10$ out of 56 , Combined type (32\%) - 18 out of 56 . Among the diagnosed 56 students with Adult ADHD characteristics, 59\% were males and 41\% were females.

In our study prevalence of Adult ADHD in medical students was found to be more in males (18.8\%) than females $(13 \%$, $p$ value 0.139$)$, urban areas (16\%) than rural areas $(15.4 \%$, $p$ value 0.884 . As recorded in the study the prevalence of ADHD was maximum in the age group of $18-20$ years, about $21 \%$ in the 18 year age group and minimum of $11 \%$ in the 25 year old ones, students older than 25 years did not report ADHD symptoms. Prevalence of Adult ADHD was maximum in MBBS students (18.8\%), followed by the Physiotherapy students (8.9\%, p value 0.015 , statistically significant), No Nursing student reported of ADHD symptoms. Level of education was found to be a statistically significant factor in association with occurrence of ADHD in adulthood. However those who had h/o rash driving, frequent road accidents, frequent quarrels, learning disabilities \& substance abuse in school, those who had other co morbid psychiatric complaints were not found to be significantly associated with ADHD in this study. Age \& gender were also found to be non-significantly associated.

\section{DISCUSSION}

The prevalence of ADHD in the study group was found to be $15.9 \%$ (56 out of 353 patients). The prevalence seems to be almost equal to that in children and much greater than those reported from studies by Fayyad et al. (0.8 - 1\%) [9], Tuttle et al. (5.5\%) [10] and Weyandtt et al. (7\%) [11]. Data regarding prevalence of adult $\mathrm{ADHD} /$ adult onset $\mathrm{ADHD}$ are conflicting with respect to populations, geographical areas etc. The estimated adult prevalence rate ranges between 3-5\%. A study in Italy, New Zealand and the US found prevalence rates of adult ADHD between 0-8.1\% among student populations [3]. Another study found that $7 \%$ of college students suffered significant ADHD symptoms, and suggested a role of these symptoms in causing problems in academic and other important areas of functioning [12]. In an anonymous survey of medical students in the US, 5.5\% reported having been diagnosed with ADHD, with $72.2 \%$ of these having been diagnosed after the age of 18 years [13].

\section{Clinical implications of the study}

Prevalence of ADHD in adults (medical students in our study) seems to be greater than usually reported. Students having ADHD are at risk of comorbid psychiatric problems like depression, learning problems and accidents [6]. It thus becomes a worthwhile measure to screen medical students for ADHD and treat wherever required and necessary. As such shtick grows old after the initial fervor so try to unravel the tangled web with available contemporary validated medical tools in their formative years.

Several major self- and clinician-rated scales are currently available to assess whether an adult meets the DSM-IV-TR criteria necessary for a diagnosis of ADHD. Certain examples of available tools are Continuous performance test, Brown ADD scale, Working memory index, Processing speed index, Barkley's current behavior scale. These are either self-reported type or clinically administered [14]. 
Table No.1: Distribution of various socio-demographic and disease related variables in association with prevalence of ADHD in the study population

\begin{tabular}{|c|c|c|c|c|c|c|}
\hline S.No & Risk factors & $\begin{array}{l}\text { ADHD } \\
\text { Present }\end{array}$ & $\begin{array}{l}\text { ADHD } \\
\text { Absent }\end{array}$ & $\begin{array}{c}\text { Total } \\
(100 \%)\end{array}$ & Chi-square value & $p$-value \\
\hline \multirow[t]{4}{*}{1.} & $\begin{array}{c}\text { Age } \\
>18-20 \text { yrs. }\end{array}$ & $44(18.33 \%)$ & $196(81.67 \%)$ & 240 & \multirow[t]{4}{*}{$8.280(\mathrm{df}=2)$} & \multirow[t]{4}{*}{$\begin{array}{l}0.688 \\
\text { (NS) }\end{array}$} \\
\hline & $20-25$ yrs. & $12(11.21 \%)$ & $95(88.78 \%)$ & 107 & & \\
\hline & $>25$ yrs. & 0 & $6(100 \%)$ & 6 & & \\
\hline & Total & $56(15.86 \%)$ & $297(84.14 \%)$ & 353 & & \\
\hline \multirow[t]{3}{*}{2.} & $\begin{array}{l}\text { Gender } \\
\text { Male }\end{array}$ & $33(18.76 \%)$ & $143(81.24 \%)$ & 176 & \multirow[t]{3}{*}{$2.190(\mathrm{df}=1)$} & \multirow[t]{3}{*}{$\begin{array}{l}0.139 \\
\text { (NS) }\end{array}$} \\
\hline & Female & $23(12.99 \%)$ & $154(87.01 \%)$ & 177 & & \\
\hline & Total & $56(15.86 \%)$ & $297(84.14 \%)$ & 353 & & \\
\hline \multirow[t]{5}{*}{3.} & Education & & & & \multirow[t]{5}{*}{$8.429(\mathrm{df}=1)$} & \multirow[t]{5}{*}{$0.015(\mathrm{~S})$} \\
\hline & M.B.B.S & $51(18.8 \%)$ & $221(81.2 \%)$ & 272 & & \\
\hline & Physiotherapy & $5(8.9 \%)$ & $51(91.1 \%)$ & 56 & & \\
\hline & Nursing & 0 & $25(100 \%)$ & 25 & & \\
\hline & Total & $56(15.86 \%)$ & $297(84.14 \%)$ & 353 & & \\
\hline \multirow[t]{3}{*}{4.} & H/O Rash & & & & \multirow{3}{*}{$2.641(\mathrm{df}=1)$} & \multirow{3}{*}{$0.267(\mathrm{NS})$} \\
\hline & $\begin{array}{l}\text { driving } \\
\text { Yes }\end{array}$ & $19(21.1 \%)$ & $71(78.9 \%)$ & 90 & & \\
\hline & No & $37(14.1 \%)$ & $226(85.9 \%)$ & 263 & & \\
\hline \multirow[t]{3}{*}{5.} & H/O Frequent & & & & \multirow[t]{3}{*}{$1.768(\mathrm{df}=1)$} & \multirow{3}{*}{$\begin{array}{c}\mathrm{P}=0.184 \\
\text { (NS) }\end{array}$} \\
\hline & $\begin{array}{c}\text { accidents } \\
\text { Yes }\end{array}$ & $21(198 \%)$ & $85(802 \%)$ & 106 & & \\
\hline & No & $35(14.2 \%)$ & $212(85.8 \%)$ & 247 & & \\
\hline \multirow[t]{3}{*}{6.} & H/O Quarrels & $18(164 \%)$ & $92(836 \%)$ & 110 & \multirow[t]{3}{*}{$0.030(\mathrm{df}=1)$} & \multirow{3}{*}{$\begin{array}{c}\mathrm{P}=0.863 \\
(\mathrm{NS})\end{array}$} \\
\hline & & & & & & \\
\hline & No & $38(15.6 \%)$ & $205(84.4 \%)$ & 243 & & \\
\hline \multirow[t]{4}{*}{7.} & H/O Learning & & & & \multirow[t]{4}{*}{$3.542(\mathrm{df}=1)$} & \multirow[t]{4}{*}{0.060 (NS) } \\
\hline & $\begin{array}{c}\text { difficulties at } \\
\text { school }\end{array}$ & & & & & \\
\hline & Yes & $31(20 \%)$ & $124(80 \%)$ & 155 & & \\
\hline & No & $25(12.6 \%)$ & $173(87.4 \%)$ & 198 & & \\
\hline \multirow[t]{6}{*}{8.} & Co-morbid & & & & \multirow[t]{6}{*}{$4.258(\mathrm{df}=1)$} & \multirow[t]{6}{*}{0.513 (NS) } \\
\hline & $\begin{array}{c}\text { disorders } \\
\text { No }\end{array}$ & $54(15.65 \%)$ & 291 (84.34\%) & 345 & & \\
\hline & Yes & $2(25 \%)$ & $6(75 \%)$ & 8 & & \\
\hline & Depression & $2(33.34 \%)$ & $4(66.66 \%)$ & 6 & & \\
\hline & Seizures & 0 & $1(100 \%)$ & $1(100 \%)$ & & \\
\hline & Phobias & 0 & $1(100 \%)$ & $1(100 \%)$ & & \\
\hline \multirow[t]{4}{*}{9.} & $\mathrm{H} / \mathrm{O}$ & & & & \multirow[t]{4}{*}{$0.755(\mathrm{df}=1)$} & \multirow[t]{4}{*}{0.385 (NS) } \\
\hline & $\begin{array}{c}\text { Substance use } \\
\text { Yes }\end{array}$ & & & 65 & & \\
\hline & & $8(12.3 \%)$ & $57(87.7 \%)$ & & & \\
\hline & No & $48(16.7 \%)$ & $240(83.3 \%)$ & 288 & & \\
\hline
\end{tabular}

Note: $\mathrm{H} / \mathrm{O}=$ History of, $\mathrm{df}=$ degree of freedom, $\mathrm{ADHD}=$ Attention Deficit Hyperkinetic Syndrome (in adults), NS=Non-significant. 
While many individuals find their ADHD impairments becoming less problematic as they get older, due to maturation of the brain or changing environmental demands, there are many for whom significant impairment persists well into their adult years. Research has shown that many individuals with ADHD find their functional impairments persist well into middle age and often beyond. In addition, bodily changes may cause late onset of ADHD like impairments, e.g. for women during and after menopause, and for both men and women as their bodies age. Extension of ADHD impairments into middle and later years of life has not yet been adequately studied.

Accurately diagnosing ADHD is critically important. Missed diagnosis and the absence of treatment were associated with educational, occupational, and social impairments in adaptive functioning, as well as an increased risk of substance use disorder. Because of the high prevalence rate of ADHD, clinicians should be aware of the symptoms and adult manifestations of ADHD and include screening in every adult psychiatric evaluation [8, 13]. It was concluded that such studies should be undertaken frequently at different geographical locations in different time frames to tackle this devastating problem in early stages. Results of this study are indicating towards tip of the iceberg. So it is recommended to undertake such studies at multicentre level with many other variables like verbal/reading abilities/audio verbal memory assessment to explore the real magnitude of the problem in different age groups.

\section{REFERENCES}

1. Brown TE. Attention Deficit Disorder: The Unfocused Mind in Children and Adults New Haven, CT: Yale University Press. JAMA 2005;18:2293-5.

2. Montes LGA, García AOH, Ricardo-Garcell J. ADHD Prevalence in Adult Outpatients With Nonpsychotic Psychiatric Illnesses. J Atten Disord 2007;11:150-6.

3. Fayyad J, de Graaf R, Kessler R, Alonso J, Angermeyer M, Demyttenaere K, et al. Cross-national prevalence and correlates of adult attention deficit hyperactivity disorder. Br J Psychiatry 2007;190:402-9.

4. Schweitzer JB, Cummins TK, Kant CA. Med Clin North Am 2001;85(3):757-77.

5. Barkley RA. Attention Deficit Hyperactivity Disorder: A Handbook for Diagnosis and Treatment. 2nd ed. 1998.

6. Biederman J, Faraone SV, Spencer T, Wilens T, Norman D, Lapey KA. Patterns of psychiatric comorbidity, cognition, and psychosocial functioning in adults with attention deficit hyperactivity disorder. Am J Psychiatry 1993;150(12):1792-8.

7. American Psychiatric Association: Diagnostic and Statistical Manual of Mental Disorders, Fourth Edition, Text Revision. Washington, DC, American Psychiatric Association. 2000.

8. Kessler RC, Adler L, Ames M, Demler O, Faraone S, Hiripi EV, Howes MJ, Jin R, Secnik K, Spencer T, Ustun TB. The World Health Organization Adult ADHD Self-Report Scale (ASRS): a short screening scale for use in the general population. Psychol Med 2005;35(2):245-56.

9. Weyandt LL, Linterman I, Rice JA. Reported Prevalence of Attentional Difficulties in a General Sample of College Students. J Psychopathol Behav Assess 1995;17(3):293-304.

10. Tuttle JP, Scheurich NE, Ranseen J. Prevalence of ADHD Diagnosis and Nonmedical Prescription Stimulant Use in Medical Students. Acad Psychiatry 2010;34:220-3.

11. Roy-Byrne P, Scheele L, Brinkley J, Ward N, Wiatrak C, Russo J, Townes B, Varley C. Adult attentiondeficit hyperactivity disorder: assessment guidelines based on clinical presentation to a specialty clinic. Compr Psychiatry 1997;38(3):133-40.

12. Barkley RA, Murphy KR. Attention-Deficit Hyperactivity Disorder: A Clinical Workbook. 2nd ed. New York, NY: Guilford Press; 1998.

13. David W. Goodman. ADHD in Adults: Update for Clinicians on Diagnosis and Assessment. Prim Psychiatry 2009;16(11):21-30.

Acknowledgements - We are thankful to Dr. Abhay Jain, Professor and Head - Dept. of Neuropsychiatry, RD Gardi Medical College, Ujjain for his kind guidance and timely help in this research work

$$
\begin{gathered}
\text { Conflict of Interest - Nil; } \\
\text { Funding - Nil. }
\end{gathered}
$$

